\title{
BYOE: A Portable Table-top Lab for Exploring Crystal Structures
}

\section{Ms. Isabelle Dutil, University of Toronto}

Isabelle Dutil recently completed her MHSc in Clinical Engineering from the Institute of Biomaterials and Biomedical Engineering at the University of Toronto in Toronto, Canada. She received her BASc in Materials Science and Engineering also from the University of Toronto in 2012. She is passionate about improving learning experiences for undergraduate students in engineering.

\section{Prof. Jun Nogami, University of Toronto}

Jun Nogami is the Chair of the Department of Materials Science and Engineering at the University of Toronto. He has a strong interest in engineering education that stems from the differences that he has observed in Engineering vs Physics pedagogy.

\section{Dr. Scott Ramsay, University of Toronto}

Scott Ramsay is currently a lecturer and Adjunct Professor Scott is currently an Adjunct Professor of Materials Science and Engineering at the University of Toronto, in Toronto, Canada, and a registered professional engineer in Ontario. Scott earned his PhD in Materials Science and Engineering from the University of Toronto in 2007. Scott's current primary academic interests are in improving the quality of undergraduate engineering education through the use of various reusable learning objects. Scott has taught extensively in Material Science, teaching courses ranging from introductory materials science to thermodynamics, diffusion, materials selection, manufacturing, biomaterials, and building science.

\section{Dr. Scott D Ramsay, University of Toronto}




\section{BYOE: A Portable Table-top Lab for Exploring Crystal Structures}

\section{Summary}

First year students often struggle to develop the spatial thinking skills required to understand crystal structures and crystallographic planes and directions. The experiment presented here is used in a tutorial setting to provide students with hands-on experience building various common crystal structures, exposing various atomic planes, and comparing their three dimensional arrangements of atoms. This experiment is one of four so-called portable tabletop labs (PTLs) that have been developed for use by roughly 2000 first year engineering students across a number of disciplines. The portable table-top labs are easily transportable and require very little set-up time, thereby facilitating their use in tutorial rooms that may be scattered geographically across campus. The crystal structure PTL includes five small Delrin ${ }^{\circledR}$ bases (roughly $100 \mathrm{~mm} \times$ $100 \mathrm{~mm}$ ) into which are machined holes corresponding to the positions of $15.9 \mathrm{~mm}$ Delrin ${ }^{\circledR}$ balls in specific crystallographic planes. These five small bases are separated into four stations where each station addresses a different crystal structures topic. Clear acrylic sides are fastened to the bases to constrain the balls, allowing the construction of simple cubic (SC), body centered cubic (BCC), face centered cubic (FCC) and hexagonal close packed (HCP) structures. The clear sides allow students to observe the structures from a range of angles.

In addition to these bases, polystyrene models of FCC, SC, and HCP are included in this PTL that can be freely rotated to help students compare crystal structures.

\section{Pedagogical Context}

Crystal structure is a fundamental topic in materials science as it provides a foundation for understanding a range of structure-property relationships. Visualization of three-dimensional structures and crystallographic directions by first year engineering students often poses a challenge as textbooks and other learning materials can utilize only two dimensional depictions. This tutorial activity allows students to build crystal structures, and to examine and compare them.

In the past, other researchers had conducted a similar activity to support student learning. Published in 1952, Hatch, R.A., et.al ${ }^{[1]}$ used hollow plastic balls for crystal structure construction in order to facilitate x-ray crystallography and crystal chemistry teaching. More recently, in 2013, Sow, C.H., et.al ${ }^{[2]}$ stacked tennis balls into a transparent box. These two sources support and justify our approach. 
However, our approach does differ from these sources. For example, the models in this experiment are much smaller than those designed by Sow et.al ${ }^{[2]}$ and therefore facilitate discussion in the classroom since they can be easily shared between students. The model size also makes them more easily transportable for TAs. In addition to this, the design of the transparent acrylic box (specifically the base) facilitates the construction of a stable crystal structure; this was not always the case with the tennis ball model according to Sow, et.al and was raised as an area of improvement by students ${ }^{[2]}$.

In addition to the different design, ball bearings of different color are added to each lab kit giving students the chance to experiment with different crystal structures. Furthermore, this experiment does include an exercise sheet to reinforce concepts observed or discussed while engaging with the models. We hypothesized that this would have a greater effect on retention compared to a discussion.

\section{Application}

Through hands-on experience building and observation of crystal structures, students can better understand a number of concepts introduced in first year materials science and engineering courses. The five Delrin ${ }^{\circledR}$ bases with acrylic sides, Delrin ${ }^{\circledR}$ balls and polystyrene models are organized into four stations (Figure 1) that each facilitate understanding of different crystal structures and concepts.

The first station challenges students to think about the relative positioning of atoms without becoming distracted by the borders of the model (Figure 1a). In addition, through construction of simple cubic and face centered cubic structures, students can observe close packed directions and planes. The concept of coordination number can be more easily demonstrated through a 3D structure as well. The second station begins with a (110) plane for either simple cubic or FCC and can be used to create either crystal structure (Figure 1b). Students typically assume the station 3 base will only allow the creation of an HCP structure; however FCC can also be created. A stacking fault can also be built, demonstrating the flexibility of this experiment (Figure 1c). Station 4 allows the creation of the BCC structure and presents a great opportunity to discuss the coordination number and direction of contact in the hard sphere model of BCC (Figure 1d) 


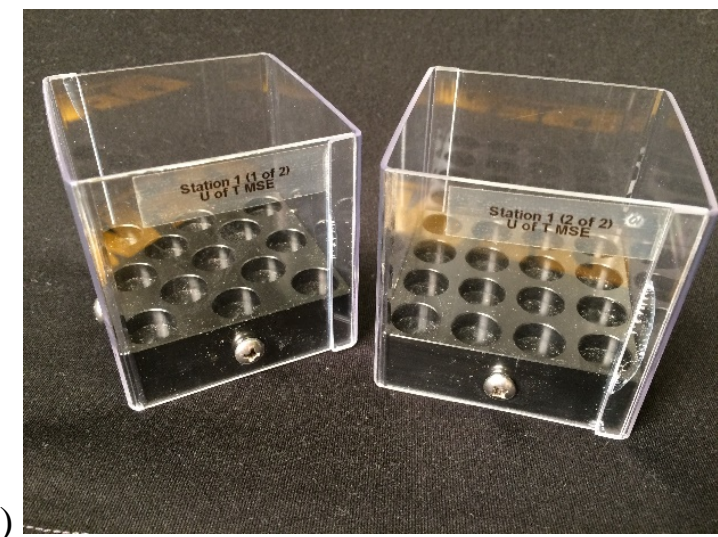

b)

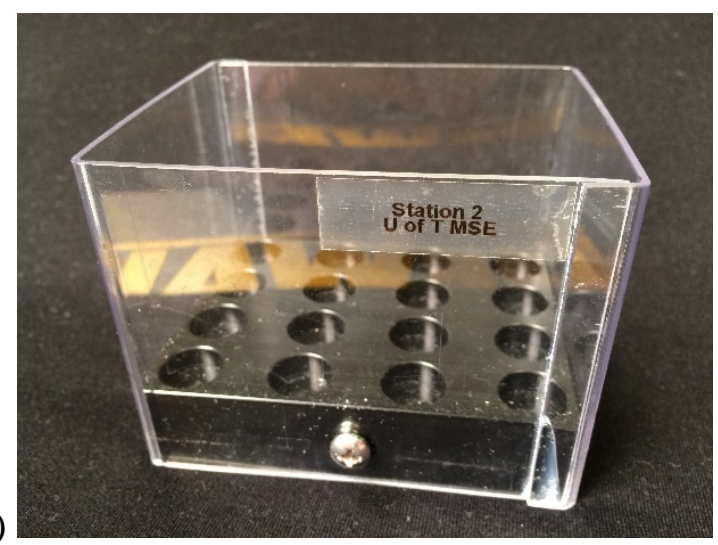

c)

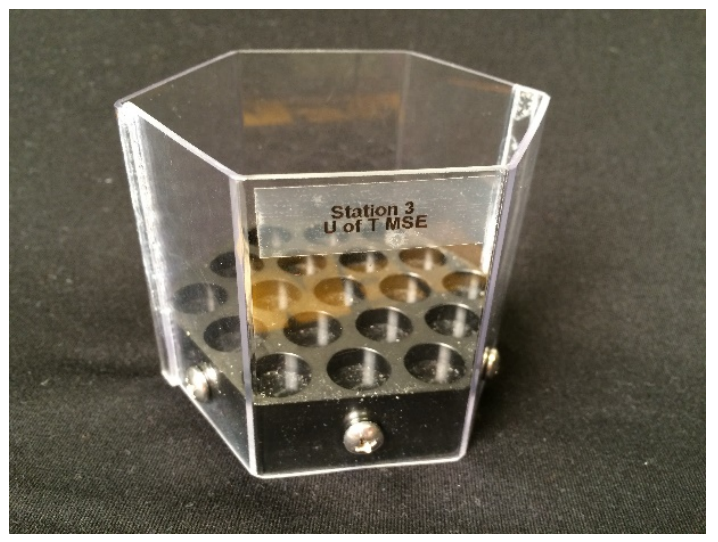

d)

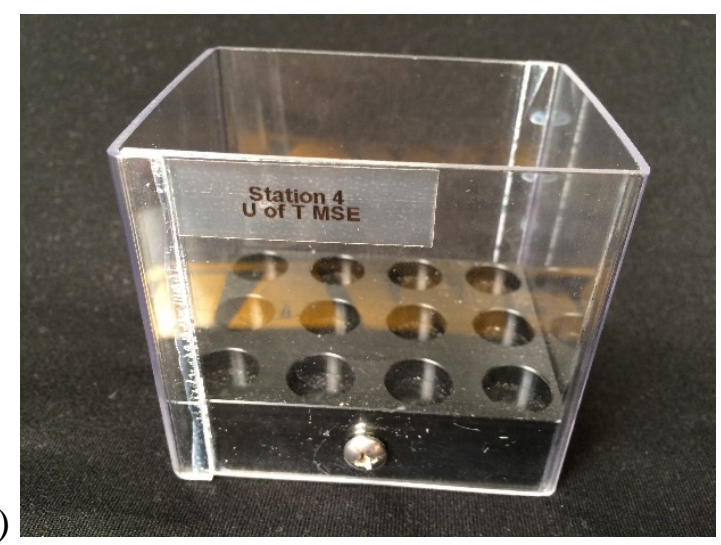

Figure 1. The five bases used in this experiment.

\section{a. Station 1}

At this station, students are presented two clear acrylic sided boxes (Figure 2). One box has the FCC (100) plane at its base while the second box's base represents the simple cubic (100) plane. This station forces students to compare the structures and notice that they are equivalent planes. 

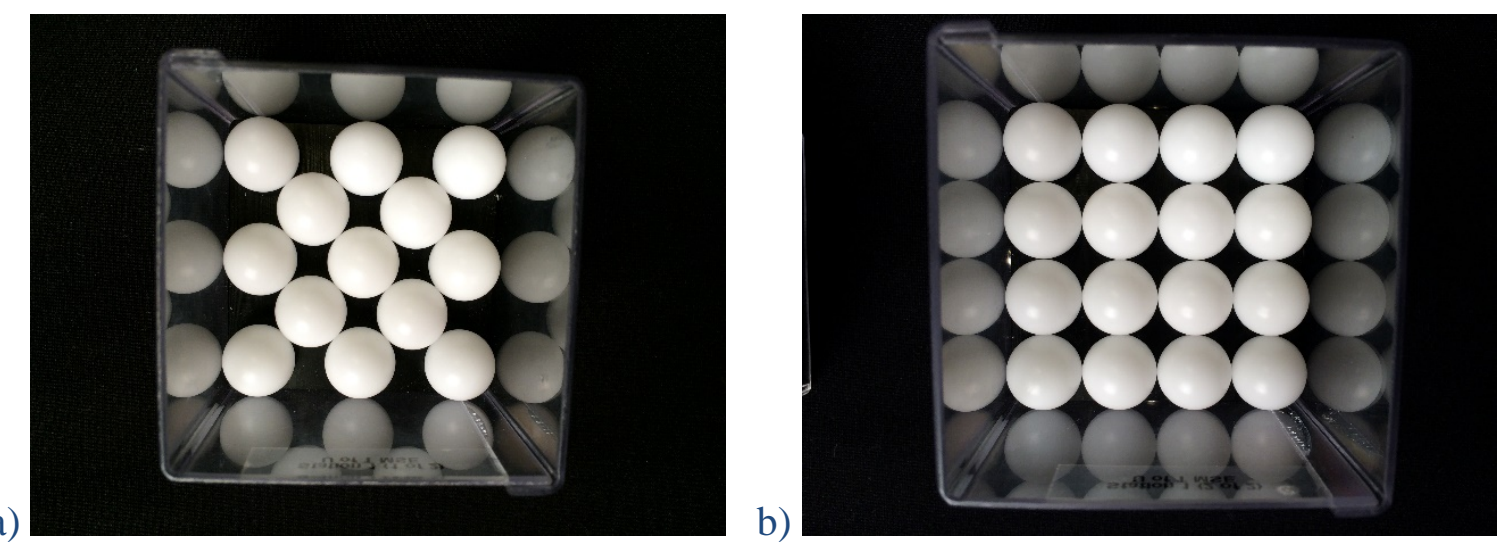

c)
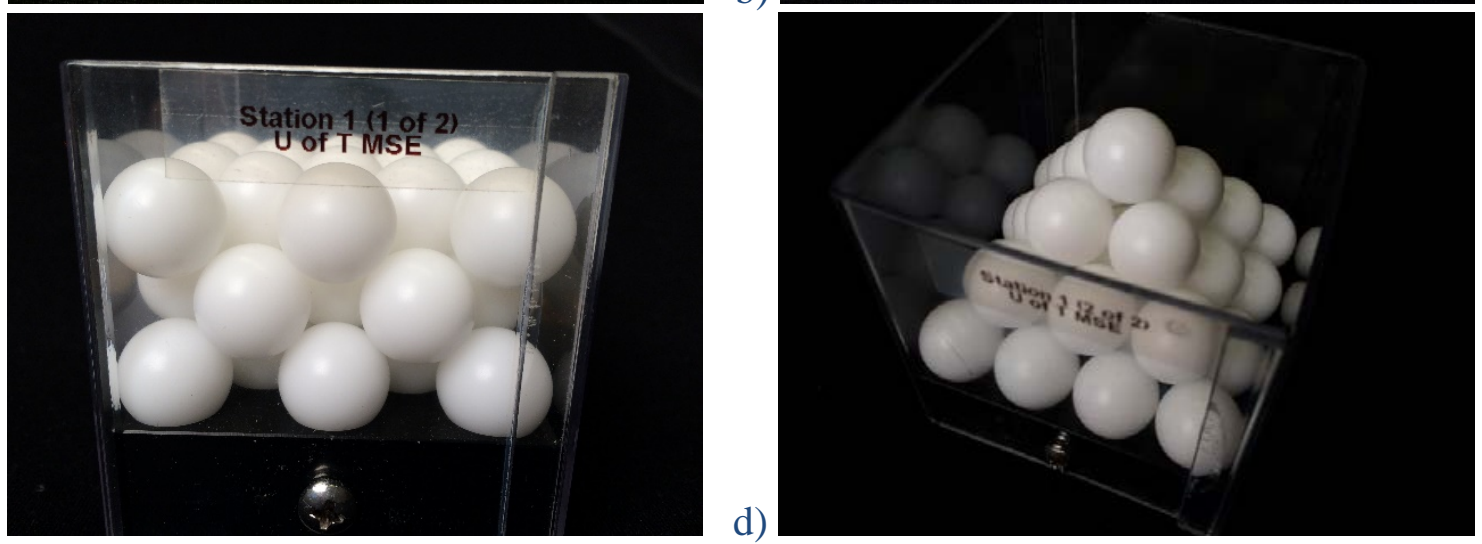

Figure 2. Some of the planes and structures that can be constructed with station 1 . This station challenges students to think about the relative positioning of atoms and not to be distracted by the borders of the model. Both a) and b) represent the $\{001\}$ planes for FCC. Additional layers added create the familiar FCC structure c) and a square based pyramid constructed from base 2 of station 1 clearly exposes the four non-parallel $\{111\}$ planes for FCC.

In addition, through construction of simple cubic and face centered cubic structures, students can observe close packed directions and planes. The concept of coordination number can be more easily demonstrated through a 3D structure as well.

\section{b. Station 2}

Students are presented with a box whose base represents the simple cubic (110) plane (Figure 3). They are asked to identify this same plane in the FCC structure. Again this reinforces the concepts of crystallographic planes not readily observable in 2D schematics. 


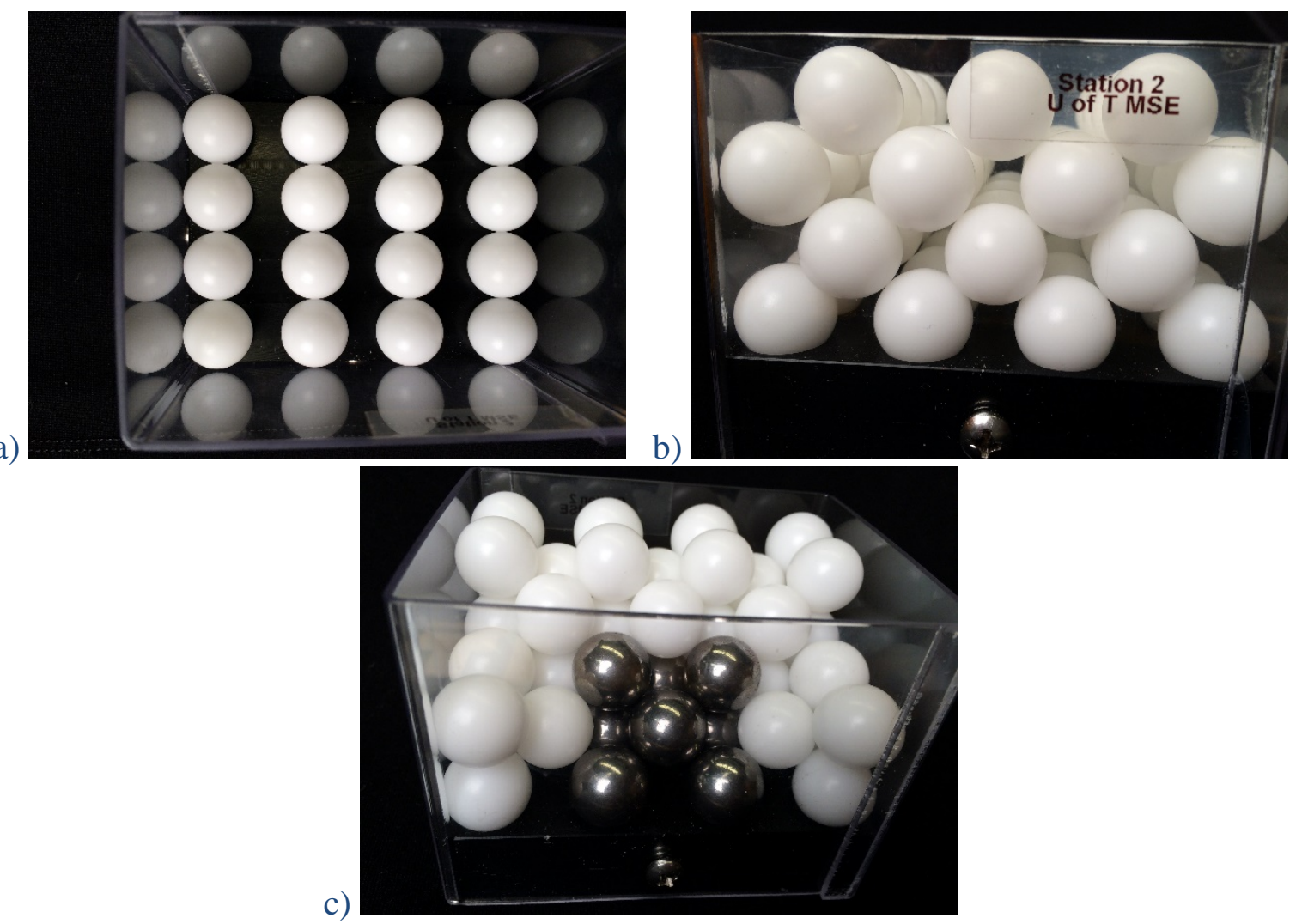

Figure 3. Station 2 begins with a (110) plane for either simple cubic b), or FCC c) and can be used to create either crystal strucutre. Steel ball bearings were used in c) to clearly illustrate the familiar FCC unit cell within the extended structure.

\section{c. Station 3}

Students are asked to build the first plane on the board and to identify the Miller indices of each plane for both FCC and HCP crystal structures. This facilitates observation and identification of close packed directions, coordination number as well as possible interstitial sites. Stacking multiple layers of plastic balls can also facilitate stacking pattern observation (Figure 4). 

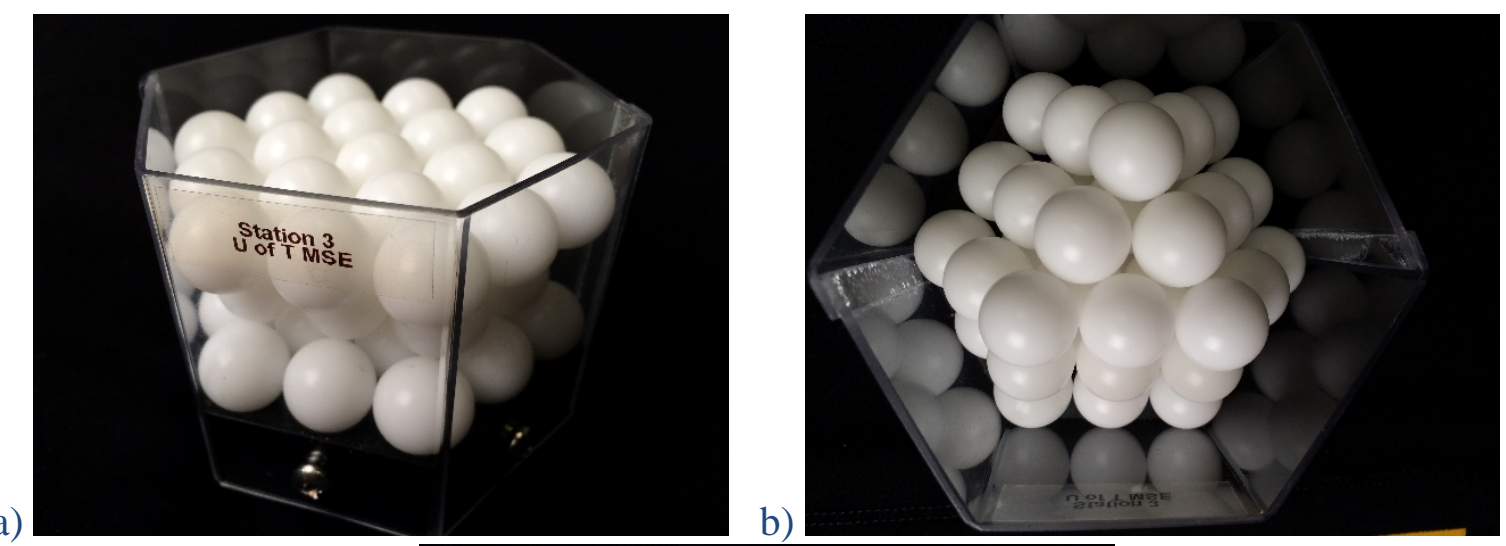

a)

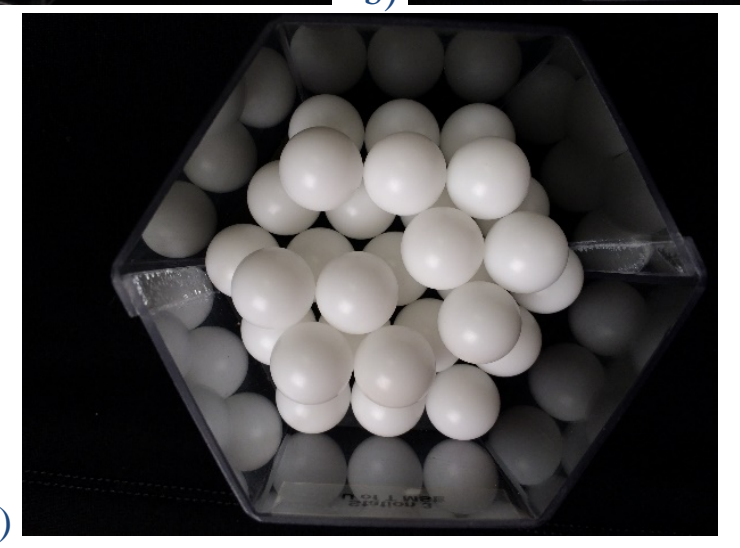

Figure 4. Some of the structures that can be created using station 3. Students typically assume the base will only allow the creation of an HCP structure a). However FCC can also be created b), and c) shows a stacking fault, demonstrating the flexibility of this experiment

\section{d. Station 4}

Presented with a ball board representing the BCC (100) plane (Figure 5), students are asked to identify it, identify any closed packed directions, determine the coordination number and if with two colors of plastic balls, identify the ceramic crystal structure that can also be created.

a)

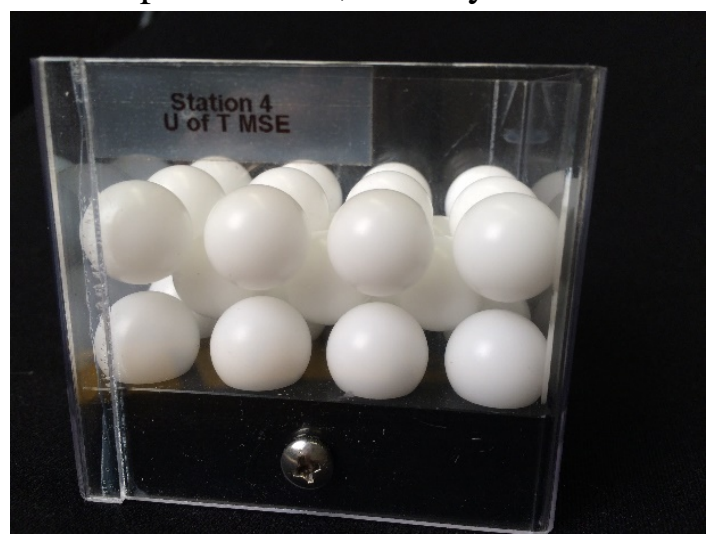

b)

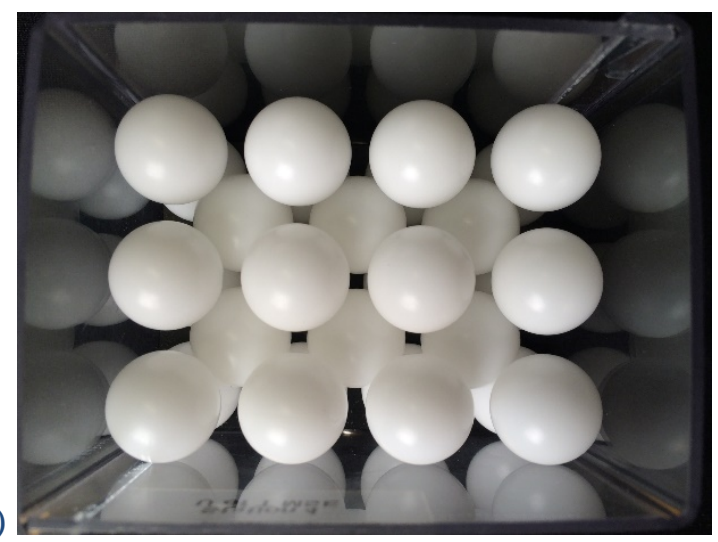

Figure 5. Station 4 allows the creation of the BCC structure and presents a great opportunity to discuss the coordination number and direction of contact in the hard sphere model of BCC. 


\section{Apparatus Design}

As mentioned above, five clear acrylic boxes are used in the tutorial experiment. The base of each box is a Delrin ${ }^{\circledR}$ board machined with blind holes which corresponds to atom positions on planes of the various crystal structures (SC, BCC, FCC and HCP). Students are then able to build the structures, enclosed in the boxes. The clear acrylic sides encourage close observation of packing patterns and better understanding of crystallographic directions and planes.

\section{Bill of Materials}

Below is the experiment's bill of materials (Table 1). This table includes all materials required per tutorial class which includes approximately 30 to 40 students. This includes the clear acrylic boxes for building the crystal structures, large scale polystyrene models (Figure 6) and the storage trolleys (Figure 7). Note that the dominant cost is the machining time for the bases which is rather high in this particular case.

Table 1: Bill of materials for experiment setup per tutorial group comprised of between 30 and 40 students

\begin{tabular}{|c|c|c|c|c|c|c|}
\hline Part & Description & $\begin{array}{l}\text { Manufacturer } \\
\text { /Supplier }\end{array}$ & $\begin{array}{l}\text { Vendor } \\
\text { part \# }\end{array}$ & $\begin{array}{l}\text { Unit } \\
\text { Price }\end{array}$ & Qty & $\begin{array}{l}\text { Extended } \\
\text { price }\end{array}$ \\
\hline Plastic balls & $\begin{array}{l}15.9 \text { mm Delrin }{ }^{\circledR} \\
\text { balls, } 25 \text { per pack }\end{array}$ & McMaster Carr & $9614 \mathrm{~K} 6$ & $\$ 9.32$ & 4 & $\$ 37.28$ \\
\hline Plexiglas box & Machined in-house & & & $\$ 100$ & 20 & $\$ 2000$ \\
\hline $\begin{array}{l}\text { Polystyrene } \\
\text { balls } \\
\text { (Figure 6) }\end{array}$ & $\begin{array}{l}34.9 \text { mm polystyrene } \\
\text { foam balls } \\
450 \text { pack }\end{array}$ & Smoothfoam $^{\mathrm{TM}}$ & 16 & $\$ 70.85$ & 0.1 & $\$ 7.09$ \\
\hline $\begin{array}{l}\text { Glue for } \\
\text { polystyrene } \\
\text { model }\end{array}$ & Hot melt glue & & & & 1 & \\
\hline $\begin{array}{l}\text { Box for } \\
\text { storage } \\
\text { (Figure 7) }\end{array}$ & $\begin{array}{l}533 \mathrm{~mm} \times 152 \mathrm{~mm} \times \\
330 \mathrm{~mm} \text { “Tough } \\
\text { System }{ }^{\circledR} \text { ” tool box } \\
\text { for storing plastic } \\
\text { balls and acrylic } \\
\text { boxes }\end{array}$ & DeWalt & DWST08201 & $\$ 49.99$ & 1 & $\$ 39.99$ \\
\hline $\begin{array}{l}\text { Large box for } \\
\text { storage }\end{array}$ & $\begin{array}{l}533 \mathrm{~mm} \times 152 \mathrm{~mm} \times \\
356 \mathrm{~mm} \\
\text { "Tough System }{ }^{\circledR} \text { ” } \\
\text { tool box for storing } \\
\text { polystyrene foam } \\
\text { models }\end{array}$ & DeWalt & DWST08204 & $\$ 69.99$ & 1 & $\$ 88.99$ \\
\hline \multirow[t]{2}{*}{$\begin{array}{l}\text { Trolley for } \\
\text { traveling } \\
\text { with lab } \\
\text { activity } \\
\end{array}$} & $\begin{array}{l}\text { Metal “Tough } \\
\text { System }{ }^{\circledR ”} \text { trolley }\end{array}$ & DeWalt & DWST08210 & $\$ 179.99$ & 1 & $\$ 143.99$ \\
\hline & & & & TOTAL & & $\begin{array}{l}\$ 2317.34 \\
\text { CAD }\end{array}$ \\
\hline
\end{tabular}



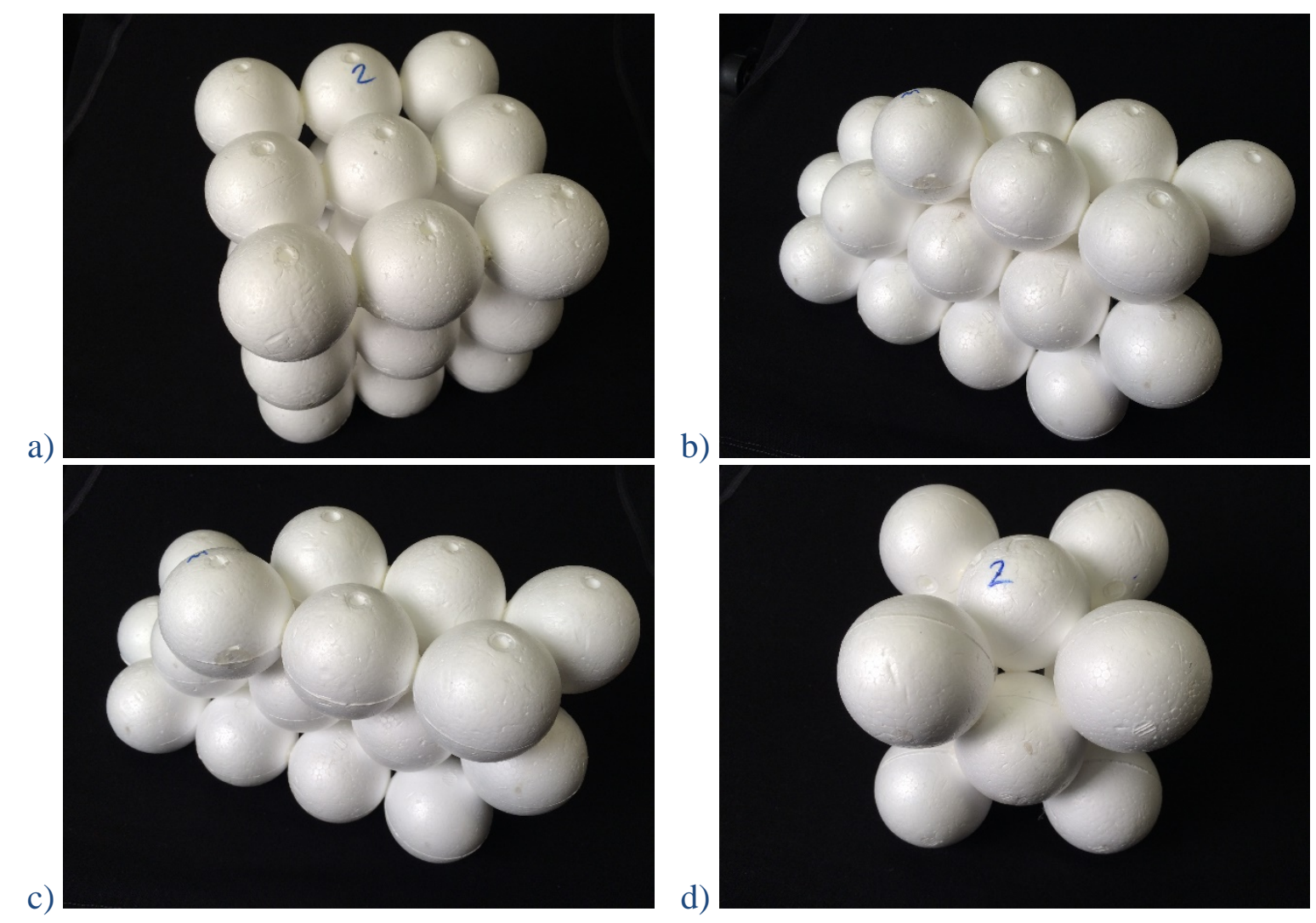

Figure 6. The polystyrene foam ball models used to support the exploration in stations 2 and 3

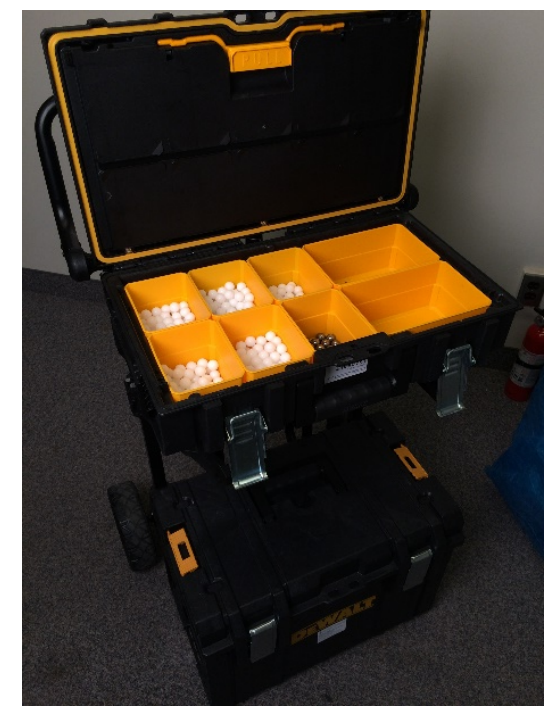

Figure 7. The DeWalt Tough System ${ }^{\circledR}$ toolbox system used to transport this experiment around campus. 


\section{Logistical Issues}

As mentioned previously, this PTL was one of several modules developed for first year materials science education, in the context of providing a hands on experience in a tutorial environment. The vision was to have a teaching assistant wheel a suitcase into a tutorial section of about 30 to 40 students, set up a number of experiment stations, and supervise an activity with a lab report template that could be completed within a 50 minute class period. For this particular lab, each section would have three complete sets of the four stations, and students in groups of three or four would rotate among the stations, spending 5 to10 minutes with each activity. There were many challenges with the scale of this project as there were typically six parallel sessions run in this way during a typical fall or winter term. The first year of implementation, there were also equipment failures with the suitcases, which were standard oversized luggage. This was exacerbated by the fact that all of the "atoms" were also steel balls, which were very heavy in the numbers required. The switch to heavy duty carrying cases along with the much lighter Delrin ${ }^{\circledR}$ “atoms” solved this issue.

There was also the question as to the best form for the lab report. Earliest versions involved either multiple choice or fill in the blank report templates. This resulted in a student focus on simply selecting the correct answers, and less open exploration of the lab. The current version of the "lab report" is simply a guide to the student, with no work handed in and only an attendance mark given. This has led to an improvement in student engagement as observed by the time students spend stacking and exploring the models and discussing with the teaching assistants as opposed to focusing on filling out the correct answers and then leaving the lab. Students had time to explore the activity and engage in discussion with other students. This guide for exploration follows as an Appendix.

\section{Evaluation of Effectiveness of Experiment}

In order to evaluate the effectiveness of this tutorial experiment, the authors distributed the Materials Science Concept Inventory (MCI) to first-year students before and after use. The first concept inventory was developed in 1985 and covered basic concepts in classical mechanics ${ }^{\text {[3] }}$. A concept inventory is a test designed to evaluate whether a student has a good understanding of a particular topic. Concept inventories are typically multiple choice questions and have been widely researched and validated. Student misconceptions are used as question responses or “distracters" in concept inventory tests ${ }^{[4]}$. The same questions are often posed multiple times, phrased differently to test interpretability. The MCI was developed by Krause et.al ${ }^{[4]}$ with question responses based on student focus groups. Misconceptions were found to be as a result of a variety of sources including personal observation, prior teaching and television shows ${ }^{[4]}$. 
The MCI is made up of four distinct categories based on the most common misconceptions of students enrolled in introductory materials science and engineering courses. These include: 1) the nature of crystalline structure and unit cells, 2) the relationship between material characteristics and bonding, 3) material processing, and 4) saturation and super-saturation ${ }^{[5]}$. The MCI can be used to identify areas for improvement in teaching approaches for introductory materials engineering courses ${ }^{[6]}$.

The authors' hypothesis was that students' performance on questions related to crystalline structures and unit cells would improve after having completed the activity. The intention of the experiment was to allow students to explore crystal structures through hands-on interaction which would in turn reinforce the theory and concepts. This test was run during the third year of implementation for this lab activity.

The MCI was distributed in tutorial to all first year students before completion of the experiment $(n=129)$. Because the MCI requires roughly 45 minutes to administer (essentially an entire 50 minute tutorial session) the authors elected to conduct the "post-experiment" concept inventory outside of class hours. Students were asked to participate on a voluntary basis only. They had the choice of completing the survey in person or online $(n=17)$.

Students were asked to complete the entire MCI even though only two questions were related to basic solid geometry (e.g. what is the number of lines that connect opposite corners of a cube through its center?) The responses to these questions were analyzed specifically.

Some 83\% of the 129 first-year engineering students (107 students) answered the first question correctly and $63 \%$ of the students (81 students) answered the second question correctly, before the activity. After the activity, 83\% of the 17 first-year students (14 students) answered the first question correctly while $65 \%$ of students (11 students) answered the second correctly.

Based on these results, there does not appear to be a significant improvement in test performance. However, there are a number of limitations to the way the MCI was used. Firstly, there were only two questions most applicable to the course content and though they reflect important knowledge, they did not directly test the concepts emphasized in the experiment (e.g. FCC vs. HCP structure).

Secondly, the post-experiment MCI was distributed outside of class and completed by volunteers. This may have biased the results as those who volunteered likely felt strongly one way or the other about the experiment. In the future, the authors will consider administering the MCI to the same students before and after the experiment. 
In addition, the experiment guide distributed to students will be altered. Though the guide will not be collected for grades, additional open-ended questions will be posed. This will give the students the opportunity to better reflect on what they have learned and may likely improve the conceptual results of the experiment.

Finally, the MCI is multiple choice and therefore not necessarily the best method to show conceptual understanding. In addition to the use of the MCI, in the future, tests and quizzes with open ended questions may also be used to evaluate understanding and retention.

Nevertheless, based on course evaluations, the activity was enjoyed by the majority of the students and allowed them to better visualize structures. We believe this to be a success as students in the past have expressed concerns regarding this topic and did not find that previous tutorial activities improved their understanding of crystal structures. Furthermore, based on the study limitations above, we also believe if the same students (and same number of students) complete the pre-and post-experiment MCI, retention will be shown to improve. Therefore, the activity will continue to be administered in first-year materials engineering classes with the refinements discussed above.

Finally, the research group has begun evaluating long term retention. A small group of upper year students volunteered to complete the Concept Inventory. Students currently in their fourth year of engineering would not have completed this particular laboratory experiment; rather they would have learned the concept of crystal structures with 2D materials from lecture slides and textbooks, etc. Those in third and second year engineering would have completed this experiment. The research group plans to continue delivering the MCI to these students annually to gather whether completing this lab in first year engineering leads to increased concept retention. As of now, the sample size is too small but efforts are being made to get the attention of a larger pool of students next year.

\section{References}

${ }^{1}$ Hatch, R.A., Comeforo, J.E., Pace, N.A., “Transparent, Plastic-ball, Crystal Structure Models,” American Mineralogist, vol.37, no.1, pp.58-68 , 1952

${ }^{2}$ Sow, C.H., Udalagama, C., Lim, G.Q., “Teaching crystal structures using a transparent box with tennis balls,” Journal of the NUS Teaching Academy, vol.3, no.1, pp.18-33, 2013

${ }^{3}$ Hallouin, I. A., \& Hestenes, D. Common sense concepts about motion (1985). American Journal of Physics, 53, 1043-1055.

${ }^{4}$ Krause, S., Tasooji, A., Griffin, R., “Origins of misconceptions in a materials concept inventory from student focus groups,” ASEE Annual Conference, 2004

${ }^{5}$ Purzer, S., Krause, S., Kelly, J., "What lies beneath the Materials Science and Engineering misconceptions of undergraduate engineering students?” 116 ${ }^{\text {th }}$ ASEE Annual Conference and Exposition, 2009 
${ }^{6}$ Krause, S.J., Kelly, J.E., Baker, D.E., “Addressing misconceptions and knowledge gaps in restructuring of atomic bonding content in a materials course to enhance student conceptual change," $118^{\text {th }}$ ASEE Annual Conference and Exposition, 2011 